\title{
A STRUCTURAL MODEL OF THE TEST FOR CREATIVE THINKING-DRAWING PRODUCTION (TCT-DP) IN ADULTS- REVISED
}

\author{
Sara Ibérico Nogueira ${ }^{1}$, Leonor Almeida ${ }^{2}, \&$ Tiago Souza Lima ${ }^{3}$ \\ ${ }^{1}$ ULHT-Universidade Lusófona de Humanidades e Tecnologias / Associate Professor (Portugal) \\ ${ }^{2} I S G$ - Business \& Economics School / Associate Professor (Portugal) \\ ${ }^{3}$ UNIFOR-University of Fortaleza / Assistant Professor (Brasil)
}

\begin{abstract}
The Test for Creative Thinking-Drawing Production (TCT-DP, Urban \& Jellen, 1996) is one of the best instruments for the creative potential assessment, which has been considered a crucial dimension in the organizational context. Considering its factorial structure, most studies have been limited using an exploratory approach. This research aims to assess the factorial structure of the TCT-DP (Form A) for a Portuguese adult sample, with a total of 620 workers, revisiting the results obtained in a study of Almeida, Ibérico Nogueira and Lima (2018). Two studies were performed. In Study 1, an exploratory factor analysis (EFA) was performed to assess the factorial structure of the TCT-DP. Take part in this study three hundred two individuals from Portugal, most of them were women $(55,6 \%)$ and had an undergrad degree $(74,8 \%)$, with age range from 18 to 86 years $(\mathrm{M}=41.1, \mathrm{SD}=10.7)$. In Study 2, there were three hundred eighteen individuals from Portugal, most of them were women $(56,6 \%)$ and had an undergrad degree $(79,9 \%)$, with age range from 19 to 70 years $(\mathrm{M}=40.6, \mathrm{SD}=10.1)$. We perform a confirmatory factor analyses aiming to replicate the factorial solution identified in Study 1. The two-factor solution (F1- Adaptiveness; F2- Innovativeness) proposed in Study 1 had acceptable to marginal fit indices: $\chi^{2}=127,8, d f=34, \chi 2 / d f=3.76, \mathrm{GFI}=.93, \mathrm{CFI}=.83, \mathrm{RMSEA}=.093, \mathrm{CI} 90 \%$ $[.076, .0111]$, ECVI $=0.54$. As in the study of 2018, two factors, Adaptiveness and Innovativeness, emerged and are composed by the same items, which led us, in the discussion, to a reflection about the parental practices features. Our model, already called TTT - Two Tracks of Thought, highlights the importance of both non-conventional and conventional thinking for the creative process.
\end{abstract}

Keywords: Creativity, TCT-DP, confirmatory factorial analysis.

\section{Introduction}

Creative thinking has been seen has a relevant dimension for those individuals and organizations that aim to reach their diversified goals, to solve their demanding problems and to be competitive and thus achieving a prolonged success (Hennessey \& Amabile, 2010). Despite the importance that has been given to creativity, organizations have not been able to promote it (Amabile, 1998). According to Halpern (2003), if we want to increase the creative potential, we must value it in the first place.

Jellen and Urban (1986) presented a comprehensive model of creativity that sustains the Test for Creative Thinking - Drawing Production (TCT-DP) that aims to evaluate several dimensions of the creative thinking, such as elaboration, composition, risk-taking, unconventional thinking and humor. The debate about the evaluation measures of creativity has unleashed one very important question related to the underlying construct of the creative assessment instruments. If some authors (e.g. Clapham, 1998) suggests its unidimensionality, Guilford (1956) and Torrance (1988) traditionally consider the multidimensionality of divergent thinking. Some other authors, namely Kim (2006), support the two-dimensionality of divergent thinking, defending the importance of both conventional and non-conventional way of thinking for the creative process. The dichotomy between divergent and convergent thinking was seen as a fake dichotomy, by Runco (2007), since developing and producing new ideas, by the divergent way of thinking, inevitably demands an evaluation and selection of the best and most appropriate ones, by the convergent way of thinking.

The study of Ibérico Nogueira, Almeida and Lima (2017) was the first to test the factor structure of the TCT-DP, through a confirmatory approach, with 969 Portuguese university students. A study of, Almeida, Ibérico Nogueira and Lima (2018) tested the factorial structure of TCT-DP for 883 Portuguese 
workers. A two-factor solution was obtained for the referred studies. The factors, called Adaptiveness and Innovativeness, seem to represent both conventional and non-conventional thinking. However, for the last study with Portuguese workers, some of the items that were part of the Adaptiveness factor, raised some questions about its pertinence. The present study aims to assess the factorial structure of the TCT-DP, through a confirmatory approach, for another Portuguese adult sample, of 620 participants in order to clarify the structure previously obtained with Portuguese workers.

\section{Method}

Testing the factor structure of the TCT-DP, a two-step approach was used. The sample originated two groups. In study 1 , the first group $(\mathrm{N}=302)$ was used for an exploratory approach aiming to investigate the factorial structure of the TCT-DP. In study 2 , the second group $(\mathrm{N}=318)$ was used, aiming to replicate, through a confirmatory approach, the factor structure observed in Study 1.

The Instruments and Procedure were the same for both studies.

\subsection{Study 1}

2.1.1. Participants. In this study, participated 302 Portuguese workers, most of them women $(55,6 \%)$, with an undergraduate degree $(74,8 \%)$, with age range from 18 to 86 years $(\mathrm{M}=41.1, \mathrm{SD}=10.7)$.

2.1.2. Instruments. Urban and Jellen (1996) developed the Test for Creative Thinking-Drawing Production (TCT-DP) aiming to assess the creative potential of individuals from five years' age. It has a figurative pattern and fourteen criteria assessment. It has good psychometric qualities for the Portuguese population (e.g. Ibérico Nogueira, Almeida, \& Lima, 2017). A sociodemographic questionnaire was also applied.

2.1.3. Procedure. Between October of 2018 and February of 2019, the authors of the present study contacted, via telephone, e-mail or in person, the directors of companies of secondary and tertiary sectors, public and private, of small, medium and large dimension. After the permission to assess either lieders or employees, the authors explained the study objectives, instruments, the confidentiality and withdraw policy.

2.1.4. Results. To assess the factor structure of the scale, an exploratory factor analysis (EFA) was performed. A principal axis factoring (PAF) was used as the extraction method with a varimax rotation. To determine the number of factors to be extracted in the final solution we use Horn's parallel analysis and the interpretability of the solution. The cut-off used for factor loading was .30. A Kaiser-Meyer-Olkin $(\mathrm{KMO}=0.71)$ and Bartlett's Test of Sphericity, $\chi^{2}(45)=612, p<.001$, indicated the sampling adequacy for the analysis. Three components had eigenvalues greater than the Kaiser criterion of 1, which accounted for $55.3 \%$ of the variance. Additionally, a parallel analysis (100 datasets; IC 95\%) indicated the extraction of two factors. A second PAF was conducted, fixing the extraction of two factors. The two factors explained $44.6 \%$ of the variance. The first factor was referred to as Adaptiveness or Conventional thinking, which explained $29.3 \%$ of the variance and retained four items (Cn-Continuations, $\mathrm{Cm}$-Completions, Bfd-Boundary-breaking being fragment dependent and Bfi-Boundary-breaking being fragment-independent), with factor loadings that ranged from .72 to .50 (Cronbach alpha $=0,72$ ). The second factor, referred to as Innovativeness or Non-conventional thinking, explained $15.3 \%$ of the variance and retained six items (Nee-New elements, Hu-Humor/emotionality, Cth-Connections to Theme, Uct-Unconventionality $\mathrm{A}, \mathrm{B}, \mathrm{C}$ and $\mathrm{D}, \mathrm{Pe}-$ Perspective and $\mathrm{Cl}$-Connections with lines) with factor loadings that ranged between .62 and .30 (Cronbach alpha $=0,63)$.

\subsection{Study 2}

2.2.1. Participants. In the second study, participated 318 workers from Portugal, most of them women $(56,6 \%)$ and with an undergraduate degree $(79,9 \%)$, with age range from 19 to 70 years $(\mathrm{M}=40.6$, $\mathrm{SD}=10.1)$.

2.2.2. Results. The confirmatory factor analyses aim to replicate the factorial solution identified in Study 1. The estimation method used was the Maximum Likelihood Estimation (MLE) using the variance-covariance matrix, and the missing cases were replaced by the mean. The two-factor solution (F1, Conventional; F2, Non-conventional) proposed in Study 1 had acceptable to marginal fit indices: $\chi 2=127,8, d f=34, \chi 2 / d f=3.76$, GFI $=.93$, CFI $=.83$, RMSEA $=.093$, CI 90\% [.076, .0111], $\mathrm{ECVI}=0.54$. All the factor loadings are statistically significant $(p<0,05)$. Both factors had acceptable values of Cronbach's alpha (F1, $\alpha=.69 ; \mathrm{F} 2, \alpha=.63)$. 


\section{Discussion and conclusion}

The aim of this study is to clarify the factorial structure of the TCT-DP for Portuguese workers. Using a confirmatory factor analysis, Study 2 replicates the factor structure of Study 1. Two factors were obtained. The Innovativeness factor includes the items related to the Unconventional way of thinking (Uct), New elements (Nee), Humor $(\mathrm{Hu})$, Perspective $(\mathrm{Pe})$, Connections to theme (Cth) and Connections with lines $(\mathrm{Cl})$. The second factor, Adaptiveness, includes more conventional items such as Continuations $(\mathrm{Cn})$ and Completions $(\mathrm{Cm})$, as well the Bfd (Boundary-breaking being fragment dependent) and Bfi (Boundary-breaking being fragment-independent), traditionally considered as evidence of the willingness to take risks undeniably being among the most creative. A two-factor solution supports the two-factor solution of the previous study with a worker sample (Almeida, Ibérico Nogueira, \& Lima, 2018) in which there were found the exactly same items for each factor. In that previous study, the inclusion in Adaptiveness factor of those items dealing with the risk assumption was puzzling, in a certain way. The confirmation with the present study led us to rethink the pertinence of this structure and to raise the hypothesis that risk-taking may be a feature present in most individuals, regardless of their levels of creativity, given that possibly due to parental educational practices, individuals are less and less censored for their less-compliant behavior. The two-factor solution, Innovativeness and Adaptiveness, and the correlation between them, suggests that both forms of thinking seem inseparable, despite they can occur at different stages of the creative process, as Runco (2007) or Jaarsveld, Lachmann and Leeuwen (2012) highlighted. Since this study was carried out with working adults, it is not possible to generalize the results to the rest of the Portuguese population. In the future, further confirmatory factor analysis studies will be conducted with other specific population groups (e.g. private schools, different education areas).

\section{References}

Amabile, T. M. (1998). How to Kill Creativity. Harvard Business Review, 76(5), 76-87.

Almeida, L., Ibérico-Nogueira, S., \& Lima, T. (2018, July). In the path of Two Tracks of Thought: A Structural Model of the Test for Creative Thinking-Drawing Production (TCT-DP) in Portuguese workers. 16th ICIE conference 2018 on Excellence, Innovation, \& Creativity in Basic-Higher Education \& Psychology - University Paris Descartes, July 3-6, 2018.

Clapham, M. M. (1998). Structure of figural forms A and B of the Torrance Tests of Creative Thinking. Educational and Psychological Measurement, 58(2), 275-283. doi: $10.1177 \% 2 f 0013164498058002010$

Finke, R. A., Ward, T. B., \& Smith, S. M. (1992). Creative Cognition: Theory, Research, and Applications. Cambridge, MA: MIT Press.

Guilford, J. P. (1956). The structure of intellect model. Psychological Bulletin, 53, 267-293.

Hennessey, B. A., \& Amabile, T. M. (2010). Creativity. Annual Review of Psychology, 61, 569-598.doi:10.1146/annurev.psych.093008.100416

Ibérico Nogueira, S., Almeida, L., \& Lima, T. S. (2017). TTT- Two Tracks of Thought: A structural model of the Test for Creative Thinking-Drawing Production (TCT-DP). Creative Research Journal, 29(2), 206-211. doi: 10.1080/10400419.2017.1303312

Jaarsveld, S., Lachmann, T., \& Leeuwen, C. V. (2012). Creative reasoning across developmental levels: Convergence and divergence in problem creation. Intelligence, 40, 172- 188. doi:10.1016/j.intell.2012.01.002

Jellen, H., \& Urban, K. K. (1986). The TCT-DP (Test for Creative Thinking - Drawing Production): An instrument that can be applied to most age and ability groups. Creative Child and Adult Quarterly, 11, 138-155.

Kim, K. H. (2006). Is creativity unidimensional or multidimensional? Analyses of the Torrance Tests of Creative Thinking. Creativity Research Journal, 18(3), 251-259. doi: 10.1207/s15326934crj1803_2

Runco, M. A. (2007). Creativity. Theories and themes: research, development, and practice. USA: Elsevier Academic Press.

Torrance, E. P. (1988). The nature of creativity as manifest in its testing. In R. J. Sternberg (Ed.), The nature of creativity: contemporary psychological perspectives (pp. 43-75). NY: Cambridge University Press.

Urban, K. K., \& Jellen, H. G. (1996). Manual of Test for Creative Thinking-Drawing Production (TCT-DP). Amsterdam: Harcourt Test Publishers. 